\title{
HYPOTHESIS
}

\section{Spinal opiate analgesia and facial pruritus: a neural theory}

\author{
PETER V. SCOTT \\ M.B., F.F.A.R.C.S.
}

\author{
H. B. J. FISCHER \\ M.B., F.F.A.R.C.S.
}

The Department of Anaesthetics, Bromsgrove General Hospital, Bromsgrove, Worcestershire B61 OBB

\begin{abstract}
Summary
Facial pruritus associated with spinal opiate analgesia in man is thought to result either from release of histamine or from imbalance of sensory modulation secondary to spread of opiate to the medulla or fourth ventricle. There is another possibility: the sensory imbalance may be secondary to rostral spread of opiate effect by nervous transmission. Evidence is adduced in support of possible anatomical pathways, and in support of a medullary 'itching centre' in man.
\end{abstract}

\section{Introduction}

Pruritus, especially facial pruritus, has proved to be an unexpected and unpleasant sequel to spinal opiate analgesia in man. Although patients may report mild itching after systemic opiate (Jaffe and Martin, 1980), symptoms after intrathecal or epidural injection can be disabling and, at worst, debilitating (Hales, 1980; Duffy, 1981). As with the other side effects-nausea and vomiting, sedation, urinary retention, and respiratory depression-there is wide variation in the reported incidence: $1-39 \%$ in surgery and gynaecology (Reiz and Westberg, 1980; Collier, 1981; Welchew and Thornton, 1982) and 25-100\% in labour (Scott et al., 1980; Baraka, Nouehid and Hajj, 1981; Srinivasan, 1981; Mok and Tsai, 1981). Why there should be such variation is not clear; it may reflect current licence in selection of technique, agent, dose, formulation and volume of injectate (Yaksh, 1981).

\section{Factors involved in opiate-induced itch}

One cause of pruritus suggested has been adulteration of opiate or its vehicle by preservatives such as antioxidants or bactericides (Mathews, 1979; McQuay et al., 1980; Reiz and Westberg, 1980). Suppliers of spinal opiate now exclude additives, prepare the drugs under nitrogen, and make them sterile by filtration or heat (Evans Medical, Macarthys Ltd., personal communications, 1981). Patients still complain of pruritus.

Another culprit might be histamine (Yaksh and Reddy, 1981). Histamine produces itch and morphine alkaloids release histamine from mast cells (Herndon, 1975). Intravenous morphine increases plasma histamine whereas the synthetic opiates butorphanol and fentanyl do not (Bernstein and Grinzi, 1981; Rosow et al., 1982). Histamine is found in the central nervous system but it is doubtful whether it is present in cerebrospinal fluid (CSF) (Davson, 1967). There is no convincing evidence to incriminate histamine as the cause of itching from spinal opiate (Yaksh, 1981). On the contrary: Bromage et al. (1981) dismiss histamine in favour of 'an imbalance of sensory modulation' secondary to rostral spread of opiate receptor blockade by ascent of opiate to the medulla and fourth cerebral ventricle.

Bromage et al. (1981) receive support from the mounting evidence in favour of a central naloxonereversible mechanism for some kinds of itch. Itching induced by butorphanol, a morphine-like analgesic which does not influence plasma histamine levels, is prevented by naloxone, the pure opiate antagonist (Bernstein and Grinzi, 1981). Facial itching from spinal morphine and diamorphine is cut short by naloxone (Baraka et al., 1981; Bromage et al., 1981; Scott and Fischer, 1982). Generalized itching from liver disease has been relieved by subcutaneous or intravenous naloxone (Bernstein and Swift, 1979; Summerfield 1980, 1981). On balance, the evidence strengths the case for an important central naloxonereversible component.

The evidence does not so readily explain how pruritus is so often confined to the upper part of the face and especially to the nostrils (Hales, 1980; Scott et al., 1980; Collier, 1981; Baraka et al., 1981; Welchew and Thornton, 1982; Scott and Fischer, 1982). Opiate, and morphine in particular, seems to 
have a strange affinity, direct or indirect, for the territory of the ophthalmic and maxillary divisions of the trigeminal nerve, strikingly manifest during labour - a circumstance which led Scott et al. (1980) to suggest a neural link.

\section{Intrathecal morphine in labour}

Intrathecal morphine is safe and effective in relieving the pain of childbirth (Scott et al., 1980; Baraka et al., 1981; Mok and Tsai, 1981; Ahmad et al., 1981) but there is a price to pay-the high frequency of pruritus. This phenomenon may reflect distant spread of morphine within CSF during labour, a property shared by local anaesthetics (Russell, 1982; Holdsworth and Roulston, 1982), or it may reflect the high plasma levels of maternal endorphin which characterize labour (Kimball, 1979; Kimball et al., 1981; Budiamal et al., 1981).

All of 12 consecutive unselected patients given morphine intrathecally for pain relief during labour complained of facial itching, especially in the nostrils (Scott et al., 1980). There was no rash. The dose was $1.5 \mathrm{mg}$ and the volume of preservative-free isobaric solution $0.15 \mathrm{ml}$. Itching was synchronous with the onset of analgesia within 15-30 min of injection at the L3-L4 interspace, was almost entirely confined to the distribution of the trigeminal nerve, was poorly relieved by antihistamine, and persisted as long as the analgesia. Hypalgesia did not spread above the lower thoracic dermatomes. There was no clinical evidence of respiratory depression; apart from 3 patients during Caesarean section the pupils were at no time observed to be constricted. The findings parallel those of Baraka et al. (1981). Scott et al. categorize facial pruritus in women in labour as 'almost pathognomonic of morphine spinal analgesia'.

Are these findings best explained by the migration of opiate molecules from a spinal site of injection to a remote site in the medulla or by migration of opiate effect within the neuraxis?

\section{Spread of opiate receptor blockade in the neuraxis}

(a) Redistribution in CSF. The key factor which determines how a drug will spread within the CSF is not mass but volume (Rieselbach et al., 1962; DiChiro, 1966; Farrar and Nolte, 1982). Rieselbach et al. (1962) injected radioactive material into the lumbar sac of CSF in humans and in primates and observed its subsequent redistribution for several hours or days by autoradiography. If the volume of injectate was no more than $0.7 \%$ of the estimated total volume of CSF then rostral spread occurred only to the mid-thoracic region (adult total CSF volume is about $140 \mathrm{ml}$ (Weston, 1916); $0.7 \%$ is about $1.0 \mathrm{ml})$. If the injectate was $3.8 \%(5.0 \mathrm{ml})$ of the estimated CSF volume, spread was to the foramen magnum. Larger volumes spread to the basal cisterns and cerebral ventricles. DiChiro (1966) found spread of radioactive material to the basal cisterns after $2 \mathrm{hr}$; he used volumes of $5.0-10.0 \mathrm{ml}(3.8-7.6 \%$ of the estimated CSF volume). The lumbar sac of CSF remained 'hot' for up to $48 \mathrm{hr}$.

If Rieselbach and DiChiro are to be believed, it is hard to see how volumes of isobaric morphine as small as $1.0 \mathrm{ml}$ (and, in women in labour, $0.15 \mathrm{ml}$ ) could migrate from the lumbar sac to the medulla or upper cervical region within 15-30 min.

(b) Redistribution in blood. Plasma concentrations of morphine after a large intrathecal dose (10-15 mg) were lower than after systemic or epidural morphine (Chauvin et al., 1981). Morphine was not detected in plasma after doses of $1 \mathrm{mg}$ (Jørgensen, Andersen and Engquist, 1981). After intrathecal injection of morphine in cats, CSF levels in the cisterna magna were less than $10 \mathrm{ng} / \mathrm{ml}$; after an equipotent intravenous dose $(1.0 \mathrm{mg} / \mathrm{kg})$ cisternal levels were greater than $100 \mathrm{ng} / \mathrm{ml}$ (Yaksh and Reddy, 1981). These results do not preclude rapid vascular spread of spinal opiate after a clinical dose in man. The question is whether the plasma concentration would be sufficient to produce side effects. No one knows, for a given drug, what the concentration must be.

(c) Neuronal spread of opiate effect. The synchro nous onset of itching in a region remote from the site of segmental analgesia suggests a direct neuronaf mechanism rather than an indirect one operating through the redistribution of injected opiate (Welchew and Thornton, 1982). By impeding neuronal transmission in the ventrolateral tracts, concurrent blockade of the spinal cord with a local anaesthetic should prevent or reduce pruritus. Thus, a literature search has failed to reveal reports of itching where a spinal opiate has been given in combination with or after the administration of an epidural or intrathecal local anaesthetic for (non-obstetric) surgery.

When a small amount of local anaesthetic is deliberately combined with intrathecal opiate $(1.0 \mathrm{mg}$ freeze-dried diamorphine and $0.25 \mathrm{mg}$ bupivacaine plain in $1.0 \mathrm{ml}$ saline; pH 6.183, specific gravity 1.004 at $37^{\circ} \mathrm{C}$ ) the incidence of itching is very low (Scott and Fischer, 1982). In a current series, of 19 patients given $1.0 \mathrm{ml}$ of the mixture at L3-L4 only one has developed nasal itching. Reversible by naloxone, it came on $16 \mathrm{hr}$ after injection, long after the effect of a small dose of bupivacaine could reasonably have been expected to last. Bupivacaine also produces a segmental level of sensory loss to pinprick, which diamorphine does not. The level has never risen above the 5th-6th thoracic dermatomes. There has been no clinical evidence of other sensory, autonomic or motor blockade.

Conversely, when spinal opiates without added 
local anaesthetic were given to 131 patients (Barron and Strong, 1981) the incidence of pruritus after intrathecal morphine was $8 \%$ (morphine $2.0 \mathrm{mg}$ in $10.0 \mathrm{ml} 0.9 \%$ saline; $n=26$ ) and after intrathecal diamorphine $12 \%$ (diamorphine $0.5 \mathrm{mg}$ in $1.0 \mathrm{ml}$ sterile water; $n=62$ ). Pruritus did not occur after epidural injection $(n=43)$.

\section{A neural theory}

There are two theories which might account for pruritus associated with spinal opiate analgesia. The first assumes the rostral migration of opiate molecules from a spinal site of injection to a remote site in the medulla. The second assumes the rostral migration of opiate effect. Evidence from animals on neuronal discharge in the ventrolateral tracts of the spinal cord (Jurna and Grossman; 1976; Jurna and Heinz, 1979) leads Yaksh to conclude: 'opiates with an action limited to the spinal cord can inhibit in a powerful fashion polysynaptic reflexes, the discharge of nociceptive neurons and the rostral transmission of nociceptive information' (Yaksh, 1981) (authors' italics). There are several possible sites where a local anaesthetic could block rostral transmission: the lateral division of the dorsal root, the tract of Lissauer, the dorsal grey columns, and the white matter of the anterolateral quadrant of the spinal cord.

\section{Evidence from anatomy}

Spinal cord. The sensation of itch is thought to be a modality of the basic sensation of pain (Hyndman and Wolkin, 1943; White et al., 1950; Savin, 1980; Summerfield, 1981). Surgical section of the anterolateral quadrant of the spinal cord for intractable pain (anterior cordotomy) also abolishes the sensation of itch in the analgesic zone, whether the itch is spontaneous or induced; the sensation of tickle, or very light touch, is unaffected (Hyndman and Wolkin, 1943; White et al., 1950). The conclusion is that the sensation of itch is mediated by nerve fibres in the anterolateral quadrant of the spinal cord having cell bodies in the dorsal grey columns and dendrites in the substantia gelatinosa (lamina II of Rexed).

The tract of Lissauer-in a sense, the 'tract' of the substantia gelatinosa-is continuous in the upper cervical region with the spinal tract of the trigeminal nerve. Its fibres, which travel only 1 or 2 segments before entry or re-entry into the cord, are derived from the lateral divisions of the dorsal root and from axones having cell bodies in the substantia. Section of the tract of Lissauer in the thoracic region results in analgesia and thermanaesthesia in a band 3 to 5 segments wide on the same side (Hyndman and Wolkin, 1943), improving the results of cordotomy.

Section of the anterolateral quadrant of the spinal cord on one side also results in preterminal degeneration in some of the sensory cranial nerves and relay nuclei (Bowsher, 1962). These include the lateral vestibular nucleus, the nucleus of the solitary tract, and the spinal (descending) nucleus of the trigeminal nerve of both sides, where most of the degeneration is in the caudal part of the nucleus.

Spinal nucleus of the trigeminal nerve. The spinal nucleus is the rostral continuation of the dorsal grey columns of the spinal cord. Commencing at the level of the third or fourth cervical segments of the spinal cord (ophthalmic division) the nucleus ascends superficially in the dorsolateral part of the medulla oblongata (maxillary division) where it lies close to the solitary nucleus. Raising a slight elevation, the tuberculum cinereum, at the level of the obex (mandibular division) it is embraced by the inferior cerebellar peduncles and the auditory and vestibular nuclei and finally travels in the lateral part of the fourth cerebral ventricle to end as the principal nucleus in the pons (Warwick and Williams, 1973; Ranson and Clark, 1959; Barr, 1979; Brodal, 1981).

Both the substantia gelatinosa of the spinal nucleus of the trigeminal nerve and the substantia gelatinosa of the spinal cord are concerned predominantly with painful and thermal sensibility, and both are rich in opiate receptors (Atweh and Kuhar, 1977; Snyder, 1977a, 1977b).

Spinal tract of the trigeminal nerve. The tract, closely applied to the spinal nucleus, becomes continuous in the upper cervical region with the tract of Lissauer. Surgical section of the tract $4 \mathrm{~mm}$ below the obex for trigeminal neuralgia results in analgesia and thermanaesthesia in the ophthalmic and maxillary distribution; the sensation of tickle is retained. To render the mandibular region analgesic, section must be made at the level of the obex (Warwick and Williams, 1973).

Fourth cerebral ventricle: nasal itching and invasive tumours. Andreev and Petkov (1975), in reviewing skin manifestations of cerebral tumours in 77 patients, found itching in 13. In 6 of the 13 itch was not generalized but was invariably confined to the nostrils; and these patients were the only ones in whom disease had infiltrated the floor of the fourth cerebral ventricle. They believe this kind of pruritus is never observed with other malignant diseases, nor with non-malignant disorders of the central nervous system, and might be accepted as pathognomonic for advanced brain tumours.

Fourth cerebral ventricle: a 'scratching centre' in animals. Koenigstein (1948) injected morphine into the cisterna magna of animals in order to provoke scratching of the face and head. Intracisternal morphine produced scratching after $0.7 \mathrm{mg} / \mathrm{kg}$ (dogs, cats, and guinea-pig) and $0.6 \mathrm{mg} / \mathrm{kg}$ (rabbits). He tried to localize the site of a possible scratch centre 
and found that complete extirpation of all brain parts situated above the auditory nuclei does not prevent scratch paroxysm-whereas scission, in a caudal direction, of the corpus restiforme (inferior cerebellar peduncle) leads to a progressively increasing restriction of the scratch movements.

Koenigstein also used alizarin blue which has a strong affinity for tissues and also acts as a pruriginous and cramps-producing substance. When it is injected intracisternally and elicits itching paroxysms, it accumulates in a certain location in the lower part of the medulla oblongata. He concluded that systematic elimination of different parts of the brain leads to the inference that a scratching centre is situated in the lower part of the medulla oblongata, bounded cranially by the auditory nuclei and caudally by the corpora restiforme.

\section{Discussion}

Circumstantial evidence leads to three conclusions. The first is that pruritus associated with spinal opiate analgesia in man has an important naloxone-reversible component. The second is that pruritus induced by spinal opiate may be referred in a distribution remote from the analgesic site of opiate action in the substantia gelatinosa of the spinal cord as a result of neuronal transmission of opiate effect. Possible anatomical pathways might include spino-trigeminal neurones in the white matter of the anterolateral quadrant of the spinal cord, synapses within the substantia gelatinosa, and intersegmental neurones in the tract of. Lissauer. The third conclusion is that there may be a 'scratching centre' in animals which lies in the medulla oblongata, bounded cranially by the auditory nuclei and caudally by the inferior cerebellar peduncles. There may be an analogous 'itching centre' in man, possibly associated with endogenous opioid activity within the spinal nucleus of the trigeminal nerve.

At the doses of opiate currently applied to the spinal cord in man by the epidural or intrathecal routes, receptors in the substantia gelatinosa are presented with overwhelming concentrations of agonist. The resulting neuronal activity may spread within the neuraxis and so produce an imbalance of sensory modulation in the caudal nucleus of the trigeminal nerve, and possibly other nuclei. The imbalance may result in the sensation of itching, possibly due to a change in synaptic activity in the neighbourhood of opiate receptors.

Thus, spinal opiate may either excite some dorsal horn cells which in turn excite some trigeminal cells or, conversely, inhibit some dorsal horn cells which normally inhibit the trigeminal system. Reversal of such effects by naloxone could be explained by local action of naloxone within the spinal cord. More likely, in view of the concentration of agonist at a spinal level, reversal could be explained by the effect of naloxone in competing for receptor sites occupied by endogenous opioids in the caudal nucleus of the trigeminal nerve.

Variations in the incidence and severity of pruritus may relate to the 'placebo response' of Summerfield (1980); or they may reflect the way in which different agents influence a given population of opiate receptors in the spinal cord.

\section{Conclusion}

Current thought assumes that naloxone, in reversing side effects, competes with exogenous opiate molecules for receptor sites in the brain stem. For one side effect at least-itching - there is another possibility: naloxone may compete with endogenous opioid molecules for those receptor sites. Opioid activity in the medulla as a consequence of an opiate-induced sensory modulation in the spinal cord may come about by a neuronal mechanism. Circumstantial evidence tends to incriminate ascending neural pathways in the anterolateral quadrant of the spinal cord, in the tract of Lissauer, and in the substantia gelatinosa. Evidence both from animals and from man suggests that a central mechanism for itch may be found in the medulla oblongata in a region bounded by the auditory nuclei and the inferion cerebellar peduncles; it may be associated with the spinal nucleus of the trigeminal nerve at, or about the level of the obex.

\section{Acknowledgments}

This article could not have been written without a supply of key references and good advice. We are most grateful to Dr J. A. Savin, the Royal Infirmary, Edinburgh, Dr I. Parkin, the Medical School, Birmingham, Dr P. C. Newbold, Hereford and Worcester Area Health Authority, Prof. P. Turner, St Bartholomew's Hospital, Prof P. D. Wall, University College, London, and Dr D. Bowsher, Pain Relief Foundation, Walton Hospital, Liverpool.

\section{References}

Ahmad, S., Hawes, D., Dooley, S., Faure, E. \& Brunner, E.A. (1981) Intrathecal morphine in a parturient with a single ventricle. Anesthesiology, 54, 515.

ANDREEV, V.C. \& PETKOV, I. (1975) Skin manifestations associated with tumours of the brain. British Journal of Dermatology, 92, 675.

ATWEH, S.F. \& KUHAR, M.J. (1977) Autoradiographic localisation of opiate receptors in rat brain. 1. Spinal cord and lower medulla. Brain Research, 123, 53.

BARAKA, A., NouEIHID, R. \& HAJJ, S. (1981) Intrathecal injection of morphine for obstetric analgesia. Anesthesiology, 54, 136.

BARR, M.L. (1979) The Human Nervous System. 3rd edn. p. 106. Harper and Row, Maryland, USA.

BARRON, D.W. \& STRONG, J.E. (1981) Postoperative analgesia in major orthopaedic surgery. Epidural and intrathecal opiate. Anaesthesia, 36, 937.

BERNSTEIN, J.E. \& GRINZI, R.A. (1981) Butorphanol-induced pruritus antagonized by naloxone. Journal of the American Academy of Dermatology, 5, 227.

BERNSTEIN, J.E. \& SWIFT, R. (1979) Relief of intractable pruritus with naloxone. Archives of Dermatology, 115, 1366. 
BOWSHER, D. (1962) The topographical projection of fibres from the anterolateral quadrant of the spinal cord to the sub-diencephalic brain stem in man. Psychiatrica et Neurologia (Basel), 143, 7.5.

Brodal, A. (1981) Neurological Anatomy in Relation to Clinical Medicine. 3rd edn. Oxford University Press, London.

Bromage, P.R., Camporesi, E.M., Durant, P.A.C. \& Nielsen, C.H. (1981) Rostral spread of epidural morphine. Anesthesiology, 55, A149.

Budiamal, L.R., Muetterties, C.L., Seltzer, J.L., Jacoby, J. \& VOGEL, W.H. (1981) $\beta$-endorphin in pregnant women at term. Anesthesiology, 55, A322.

Chauvin, M., Sami, K., Schermann, J.M., Sandouk, P., BourDON, R. \& VIARS, P. (1981) Plasma concentration of morphine after i.m., extradural and intrathecal administration. British Journal of Anaesthesia, 53, 911.

COLlier, C.B. (1981) Epidural morphine. Anaesthesia, 36, 67.

Davson, H. (1967) Physiology of the Cerebrospinal Fluid, p. 218. J. and $A$. Churchill, London.

DiCHIRo, G. (1966) Observations on the circulation of the cerebrospinal fluid. Acta Radiologica (Diagnosis), 5, 988.

DUFFY, B.L. (1981) Itching as a side effect of epidural morphine. Anaesthesia, 36, 67.

FARRAR, M.D. \& NOLTE, H. (1982) Spinal analgesia using bupivacaine 0.5\%. Anaesthesia, 37, 91.

HaLeS, P. (1980) Pruritus after epidural morphine. Lancet, it, 204.

HERNDON, P. (1975) Itching: the pathophysiology of pruritus. International Journal of Dermatology, 14, 465.

HOLDSWORTH, J.D. \& RoulSTON, R.G. (1982) An unusually high block following intrathecal bupivacaine. Anaesthesia, 37, 347.

HYNDMAN, O.R. \& WOLKIN, J. (1943) Anterior chordotomy. Further observations on physiologic results and optimum manner of performance. Archives of Neurology and Psychiatry, 50, 129.

JAFFE, J.H. \& MARTIN, W.R. (1980) Opioid analgesics and antagonists. In: The Pharmacological Basis of Therapeutics, (Ed by Gilman, A.G., Goodman, L.S. \& Gilman, A.) 6th edn, p. 499. Macmillan, New York.

JøRGENSEN, B.C., ANDERSEN, H.B. \& ENGQUIST, A. (1981) CSF and plasma morphine after epidural and intrathecal application. Anesthesiology, 55, 714.

JURNA, I. \& GROSSMAN, W. (1976) The effect of the activity evoked in ventrolateral tract axons of the cat spinal cord. Experimental Brain Research, 24, 473.

JURNA, I. \& HEINZ, G. (1979) Differential effects of morphine and opioid analgesics and $\mathrm{A}$ and $\mathrm{C}$ fibre-evoked activity in ascending axons of the rat spinal cord. Brain Research, 171, 573.

KIMBALL, C.D. (1979) Do endorphin residues of beta lipotropin in hormone reinforce reproductive functions? American Journal of Obstetrics and Gynecology, 134, 127.

Kimball, C.D., Chang, C.M., Huang, S.M. \& HouCK, J.C. (1981) Immunoreactive endorphin peptides and prolactin in umbilical vein and maternal blood. American Journal of Obstetrics and Gynecology, 140, 157.

KoEnigstein, H. (1948) Experimental study of itch stimuli in animals. Archives of Dermatology and Syphilology (Chicago), 57, 828.

MATHEWS, E.T. (1979) Epidural morphine. Lancet, i, 673.
MCQUaY, H.J., BUllinghaM, R.E.S., Evans, P.J.D., LlOYD, J.W. \& MOORE, R.A. (1980) Demand analgesia to assess pain relief from epidural opiates. Lancet, i, 768.

MoK, M.S. \& TSAI, S.K. (1981) More experience with intrathecal morphine for obstetric analgesia. Anesthesiology, 55, 481.

RANSON, S.W., ClaRK, S.L. (1959) The Anatomy of the Nervous System. 10th edn, pp. 37, 187 \& 240. W. B. Saunders, Philadelphia and London.

REIZ, S. \& WESTBERG, M. (1980) Side-effects of epidural morphine. Lancet, ï, 203.

Rieselbach, R.E., DiChiro, G., Freireich, E.J. \& RAll, D.P. (1962) Subarachnoid distribution of drugs after lumbar injection. New England Journal of Medicine, 267, 1273.

Rosow, C.E., Moss, J., Philbin, D.M. \& Savarese, J.J. (1982) Histamine release during morphine and fentanyl anesthesia. Anesthesiology, 56, 93.

RUSSELL, I.F. (1982) Intrathecal bupivacaine 0.5\% for Caesarian section. Anesthesia, 37, 346.

SAviN, J. (1980) Itching. In: Recent Advances in Dermatology, Number 5 (ed by Rook, A. and Savin, J.) p. 221. Churchill Livingstone, Edinburgh, London and New York.

ScotT, P.V., Bowen, F.E., Cartwright, P., Mohan Rao, B.C., DeEleY, D., WotherspoON, H.G. \& SUMReIN, I.M.A. (1980) Intrathecal morphine as sole analgesic during labour. British Medical Journal, 281, 351.

SCOTT, P.V. \& FISCHER, H.B.J. (1982) Intraspinal opiates and itching: a new reflex? British Medical Journal, 284, 1015.

SNYDER, S.H. (1977a) Opiate receptors in the brain. New England Journal of Medicine, 296, 266.

SNYDER, S.H. (1977b) Opiate receptors and internal opiates. Scientific American, 236, 44.

SRINIVASAN, T. (1981) Intrathecal morphine for obstetric analgesia. Anesthesiology, 55, A298.

SUMMERFIELD, J.A. (1980) Naloxone modulates the perception of itch in man. British Journal of Clinical Pharmacology, 10, 280.

SUMMERFIELD, J.A. (1981) Pain, itch and endorphins. British Journal of Dermatology, 105, 725.

WARWICK, R. \& WILLIAMS, P.L. (1973) Gray's Anatomy. 35th ed. pp. $830,845,875,878,1001$. Longman Group, Edinburgh.

WelChew, E.A. \& THORNTON, J.A. (1982) Continuous thoracic epidural fentanyl. A comparison of epidural fentanyl with intramuscular papaveretum for postoperative pain. Anaesthesia, 37, 309.

WESTON, P.G. (1916) Sugar content of the blood and spinal fluid of insane subjects. Journal of Medical Research, 35, 199.

WhITE, J.C., SWEET, W.H., HAWKINS, R. \& Nilges, R.G. (1950) Anterolateral cordotomy: results, complications and causes of failure. Brain, 73, 346.

YAKSH, T.L. \& REDDY, S.V.R. (1981) Studies in the primate on the analgetic effects associated with intrathecal actions of opiates, alpha-adrenergic agonists and baclofen. Anesthesiology, 54, 451.

YAKSH, T.L. (1981) Spinal opiate analgesia: characteristics and principles of action. Pain, 11, 293. 